IMDS

117,9

1866

Received 22 September 2016 Revised 20 November 2016

7 January 2017

4 March 2017

Accepted 7 March 2017

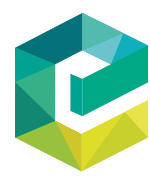

Industrial Management \& Data Systems

Systems
Vol. 117 No. 9, 2017

pp. $1866-1889$

Emerald Publishing Limited

0263-5577

DOI 10.1108/IMDS-09-2016-0389

\section{How to evaluate sustainability of supply chains? A dynamic network DEA approach}

\author{
Vahid Shokri Kahi \\ Department of Management and Accounting, Karaj Branch, \\ Islamic Azad University, Karaj, Islamic Republic of Iran \\ Saeed Yousefi \\ Pegah Distribution Company, \\ Karaj, Islamic Republic of Iran \\ Hadi Shabanpour \\ Karaj Branch, Islamic Azad University, \\ Karaj, Islamic Republic of Iran, and \\ Reza Farzipoor Saen \\ Department of Industrial Management, Karaj Branch, \\ Islamic Azad University, Karaj, Islamic Republic of Iran
}

\begin{abstract}
Purpose - The purpose of this paper is to develop a novel network and dynamic data envelopment analysis (DEA) model for evaluating sustainability of supply chains. In the proposed model, all links can be considered in calculation of efficiency score.

Design/methodology/approach - A dynamic DEA model to evaluate sustainable supply chains in which networks have series structure is proposed. Nature of free links is defined and subsequently applied in calculating relative efficiency of supply chains. An additive network DEA model is developed to evaluate sustainability of supply chains in several periods. A case study demonstrates applicability of proposed approach.

Findings - This paper assists managers to identify inefficient supply chains and take proper remedial actions for performance optimization. Besides, overall efficiency scores of supply chains have less fluctuation. By utilizing the proposed model and determining dual-role factors, managers can plan their supply chains properly and more accurately.

Research limitations/implications - In real world, managers face with big data. Therefore, we need to develop an approach to deal with big data.

Practical implications - The proposed model offers useful managerial implications along with means for managers to monitor and measure efficiency of their production processes. The proposed model can be applied in real world problems in which decision makers are faced with multi-stage processes such as supply chains, production systems, etc.

Originality/value - For the first time, the authors present additive model of network-dynamic DEA. For the first time, the authors outline the links in a way that carry-overs of networks are connected in different periods and not in different stages.
\end{abstract}

Keywords Data envelopment analysis, Sustainable supply chain management, Efficiency evaluation, Food supply chain, Dynamic DEA, Network DEA, Slacks-based measure

Paper type Research paper

(C) Vahid Shokri Kahi, Saeed Yousefi, Hadi Shabanpour and Reza Farzipoor Saen. Published by Emerald Publishing Limited. This article is published under the Creative Commons Attribution (CC BY 4.0) licence. Anyone may reproduce, distribute, translate and create derivative works of this article (for both commercial \& non-commercial purposes), subject to full attribution to the original publication and authors. The full terms of this licence may be seen at: http://creativecommons.org/ licences/by/4.0/legalcode

Authors would like to appreciate helpful comments of two anonymous reviewers. 


\section{Introduction}

Supply chain is a purposeful combination of interconnected and interdependent organization. Although, units of supply chains are separated legally, they are connected by flow of material, information, and finance. Providing the best combination of resources via outsourcing is the main issue of supply chain management (SCM) in modern business enterprises (Ageron et al., 2012). Price, quality, flexibility, and supplier reputation are economic criteria in SCM evaluation (Bai and Sarkis, 2010).

Nowadays, sustainability factors play a critical role in long-term achievement of SCM; accordingly, purchasing process becomes more complicated with social and environmental pressures. As Govindan et al. (2013) addressed, over the past decades, due to rapid reduction of natural resources, concerns over wealth inequality and corporate social responsibility, sustainability has become important for researchers and scholars. In other words, there are pressures which force SCM to focus not only on economic but also on social and environmental criteria (Dyllick and Hockerts, 2002). Thus, sustainable supply chain may be of great importance attributable to surging environmental conservation and societal prosperity while reinforcing economic intention of organization. To do so, companies should conserve resources, optimize processes, uncover product innovations, save costs, increase productivity and promote corporate values by managing and improving environmental, social, and economic performances across supply chains (Seuring and Müller, 2008). On the other hand, there are several sustainability criteria which complicate SCM's evaluation. This means that decision-makers encounter some discretionary/free and even contradictory criteria while evaluating sustainability of SCM. Dual-role links, inputs, desirable and undesirable outputs are some of the main criteria.

In an accurate appraisal of supply chain, interactions among suppliers should be taken into consideration. To evaluate sustainability of SCM, dealing with multiple criteria has been one of the significant concerns in preceding models (Yousefi et al., 2016). To deal with multiple criteria, this paper develops a novel network-dynamic data envelopment analysis (DEA) model. Wong et al. developed two DEA models including technical efficiency and cost efficiency models to explain application of DEA in measuring supply chain performance. Traditional DEA models measure relative efficiency of decision-making units (DMUs) (Charnes et al., 1978; Tavassoli et al., 2014).

However, one of the most growing criticisms in these sorts of models is that the DMUs are assessed in a specific period. Given fluctuations in performance of DMUs during several periods, considering just a specific period is insufficient in comprehensive efficiency evaluation. In dynamic DEA presented by Tone and Tsutsui (2010), the DMUs' efficiencies are assessed during several periods. However, dynamic DEA does not deal with DMUs' internal structures. Network DEA (NDEA) deals with DMUs with internal structures (Yu and Lin, 2008). Tone and Tsutsui (2014) proposed network-dynamic DEA model in which the DMUs were assessed in multiple periods with internal interactions. Their model is based upon slack-based measure (SBM) model.

Objective of this paper is to improve the dynamic DEA model proposed by Tone and Tsutsui (2014). To this end, we develop a novel dynamic DEA model with network structure in which, for the first time, the overall carry-overs of a network in period $(t)$ enter next period $(t+1)$. Note that Tone and Tsutsui (2014) connected multiple stages in different periods. In Tone and Tsutsui (2014), the carry-overs of each stage inside period $(t)$ enter the next period $(t+1)$ separately and independently. However, in our proposed approach, the overall values of carry-overs for each network are obtained and enter the next period. In other words, Tone and Tsutsui (2014) connected the stages to each other (among periods) but we connect each network (as a whole) to other networks. Hence, as it is shown in Figure 1, we consider each period $(t)$ as a network which enters next period $(t+1)$ by carry-overs. Here, in addition, free links among periods are defined in terms of desirable and undesirable carry-overs. Figure 1 displays our novel network dynamic DEA structure. Note that all notations in Figure 1 are defined in Section 3. 
IMDS 117,9

1868
Figure 1.

Typical structure of dynamic model with network structure
Despite Tone and Tsutsui (2014), our proposed approach has following advantages: our approach connects the periods by networks' carry-overs and not stages' carry-overs; we define nature of free links and apply them in calculating relative efficiency of supply chains (DMUs); we develop an additive NDEA model for evaluating sustainability of supply chains in several periods.

There are numerous criticisms directed at the model proposed by Tone and Tsutsui (2014). In the aforementioned model multiple networks are simultaneously introduced as efficient units; therefore, the model fails in ranking the supply chains (DMUs). Second, the types of link among periods have dominant weakness. Changing an inefficient period to efficient period by the solution suggested by Tone and Tsutsui (2014), causes other periods to become inefficient. In other words, by increasing output of a period, inputs of next periods will be increased. This causes inefficiency of next periods. This happens due to poor definition of links in Tone and Tsutsui (2014) model. To address this weakness, we use different method. Besides, in our model the links among networks in periods are connected in an integrated way.

It is noteworthy that Tone and Tsutsui (2014) did not determine nature of the free links and also ignored the free links in calculation of DMUs' efficiency. In other words, in the approach proposed by Tone and Tsutsui (2014), decision maker cannot identify whether a free link is a desirable or undesirable factor. Note that a free link connects two periods and consists of desirable and undesirable types (Yousefi et al., 2016). Tone and Tsutsui (2014) did not clarify nature of free links. Hence, in this paper not only do we define the nature of free links but we also use all the links in assessing sustainability of supply chains (DMUs). In this paper, the links are classified into three categories, i.e. desirable, undesirable and free links which join multiple periods in series form. Note that our proposed network-dynamic DEA model is based upon additive model in which both networks and links have series structure and each period is a network.

Next sections of the paper are as follows: Literature review is presented in Section 2. In Section 3, proposed model is given. Case study is discussed in Section 4. Obtained results and concluding remarks are presented in Section 5. In Section 5.2, managerial implications are given.

\section{Literature review}

\subsection{DEA and sustainable supply chain evaluation}

Organizations are responsible for their environmental and social performance (Zhu et al., 2005). Sustainable development emphasizes on environment, economy, and society. Evaluating sustainable supply chain management (SSCM) performance is a key challenge (Tseng et al., 2015). SSCM has turned out to be a strategic process which enables firms to create competitive advantage. Customers' demands and products' complexity have increased competition among organizations. SSCM provides an opportunity for organizations to distinguish itself from its competitors. Thus, it provides a competitive advantage in market (Khodakarami et al., 2015). Numerous organizations have already commenced to develop a certain level of commitment toward sustainability practices to make their supply chains

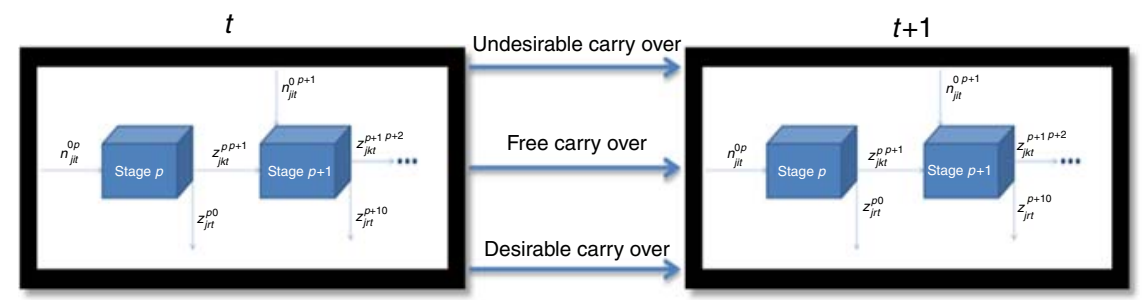


sustainable (Govindan et al., 2015). SSCM evaluation, hence, is a substantial duty for any types of organizations. Among evaluation methods, DEA appears to be a suitable technique to assess SSCM.

DEA measures relative efficiency of DMUs (Charnes et al., 1978). DEA has been used in assessing supply chains (Liang et al., 2006). To measure efficiency of supply chains, Chen et al. (2006) developed a DEA-game model. Yu et al. (2010) assessed efficiency of supply chains by cross-efficiency DEA model without considering internal structure of supply chains. To measure performance of supply chains, Wong and Wong (2007) determined technical efficiency and cost efficiency of supply chains. Wong et al. (2008) developed a method for assessing efficiency of supply chains by stochastic DEA model. One of the DEA applications is to evaluate efficiency of two-stage processes where all outputs of the first stage are intermediate measures which are considered as inputs of the second stage. As a result, two-stage DEA models assess both overall efficiency score of whole process and each of the individual stages (Khodakarami et al., 2015). DEA, furthermore, has been used to evaluate environmental and social performance of various settings (Sueyoshi and Goto, 2010; Noorizadeh et al., 2011; Rashidi et al., 2015; Azadi et al., 2015). Sueyoshi and Goto (2010) used DEA to assess effectiveness of US clean air act in controlling $\mathrm{CO}_{2}$ emission. Rashidi et al. (2015) applied DEA to estimate energy saving and undesirable output abatement of 25 countries. To assess sustainability of supply chains, Wu et al. (2016) provided both theoretical and quantitative tool.

Nevertheless, as previously mentioned, in classical models of DEA internal interactions are neglected. Given that sustainable supply chains encompass a complex network of connections and interactions, traditional DEA models have been evolved to overcome the shortcomings.

\subsection{NDEA and dynamic DEA}

To evaluate efficiency of a DMU, Färe and Grosskopf $(1996,2000)$ proposed an NDEA model with multiple production stages. Over the last decade, a couple of radial NDEA models have been presented (e.g. Lewis and Sexton, 2004; Färe et al., 2007; Kao and Hwang, 2010; Cook et al., 2010). Lewis and Sexton (2004) applied an NDEA model to evaluate organizational efficiency of companies with complex internal structure. Kao and Hwang (2010) utilized NDEA to measure efficiency of network systems taking into account IT impact on firm performance. Färe et al. (2007) developed an NDEA model by modeling data structures irregularities and structural complexities in DEA. Cook et al. (2010) selected the best supply chains by NDEA model. Liang et al. (2006) developed a non-linear model to determine efficiency of supply chains and their members. Chen and Yan (2011) presented a radial NDEA model to measure efficiency of supply chains. Yousefi et al. (2015) developed an NDEA model by goal programming to select the best supply chains.

For the first time, Sengupta (1995) introduced dynamic DEA model (D-DEA) and later it was extended based on the studies of Färe and Grosskopf (1996). They proposed a dynamic production frontier using an intermediate output which relates annual production processes. However, developing a new dynamic slacks-based measure (DSBM) model by Tone and Tsutsui (2010) was a turning point in the D-DEA literature. They suggested four types of carry-overs (links); desirable, undesirable, discretionary, and non-discretionary (fixed) links to assess DMUs in different periods. The paper proposed by Tone and Tsutsui (2014) may be considered as one of the most comprehensive and reliable methods to evaluate sustainability of supply chains. They, for the first time, merged network SBM and DSBM models. By so doing, they proposed a dynamic DEA model with network structure. However, they did not specify some important items in their model.

\section{A dynamic network DEA approach}

1869 
IMDS

117,9

1870

\subsection{The proposed approach's necessity}

In traditional DEA models as well as current dynamic DEA models, internal processes within the DMUs are not considered. In a comprehensive and realistic assessment of DMUs (networks), internal structures should be assessed. This means that all links among and inside the DMUs (networks) should be appropriately considered and defined. Unlike the real world, Tone and Tsutsui (2014) applied stages as periods and not networks and they ignored to explicitly define nature of free links in their model. In other words, they overlooked to determine whether free links are desirable or undesirable. Hence, they ignored to employ free links in calculating efficiency of DMUs.

This paper intends to address these gaps. Indeed, very few papers so far have considered all the aforementioned criteria along with sustainability in supply chain using an optimization approach. For the first time, in this paper, a network-dynamic DEA model is proposed which is able to assess sustainability of supply chains in different periods. It should be mentioned that the connections among periods are as the links among networks and not stages. Besides, this model can assess sustainability of supply chains in multiple periods using additive model of network-dynamic DEA. In summary, contributions of this paper are as follows.

- for the first time, we present additive model of network-dynamic DEA;

- we develop temporal link among networks based on series view;

- we utilize the free links and determine their nature; and

- for the first time, we outline the links in a way that carry-overs of networks are connected in different periods and not in different stages.

\section{Proposed method}

\subsection{Algorithm}

To introduce our proposed method, following steps are taken: In step 1, we provide data set as inputs, outputs, and links for each supply chain. In step 2, our dynamic NDEA model is run to evaluate sustainability of supply chains. In step 3, rank of supply chains is determined and the best sustainable supply chain is introduced. These steps are presented in Figure 2.

\subsection{Definition of variables, network structure of supply chains, and dynamic DEA}

At this juncture, as is shown in Figure 3 , the network model is defined. Here, $n_{j i t}^{0 p}$ represents $i$ th input $(i=1, \ldots, I)$ of $j$ th $\operatorname{DMU}(j=1, \ldots, m)$ in $t$ th period $(t=1, \ldots, T)$ which feeds stage $p$ from outside. $z_{j k t}^{p p+1}$ indicates $k$ th output $(k=1, \ldots, K)$ of $j$ th $\operatorname{DMU}(j=1, \ldots, m)$ in $t$ th period $(t=1, \ldots, T)$ as output of stage $p(p=1, \ldots, P)$ which feeds stage $p+1$ as input. $z_{j r t}^{p 0}$ signifies $r$ th output $(r=1, \ldots, s)$ of $j$ th $\operatorname{DMU}(j=1, \ldots, m)$ in $t$ th period $(t=1, \ldots, T)$ as output of stage $p(p=1, \ldots, P)$ which exits from network.

The relevant multipliers (weights) of the above factors are defined as follows:

- $\lambda_{p r}$ : multiplier of the output $z_{j r t}^{p 0}$ exiting from stage $p$.

- $\beta_{p k}$ : multiplier of the output $z_{j k t}^{p p+1}$ which exits the stage $p$ and enters stage $p+1$.

- $\alpha_{p i}$ : multiplier of the input $n_{j i t}^{0 p}$ entering the network at beginning of stage $p$ from outside.

Now, the efficiency of stage 1 in $t$ th period is defined as follows. It should be noted that the first stage is the only stage in which all inputs enter the network from outside and not from prior stage:

$$
\rho_{1 j}=\frac{\sum_{r=1}^{s} \lambda_{p r} z_{j r t}^{10}+\sum_{k=1}^{K} \beta_{p k} z_{j k t}^{12}}{\sum_{i=1}^{I} \alpha_{p i} n_{j i t}^{01}}
$$




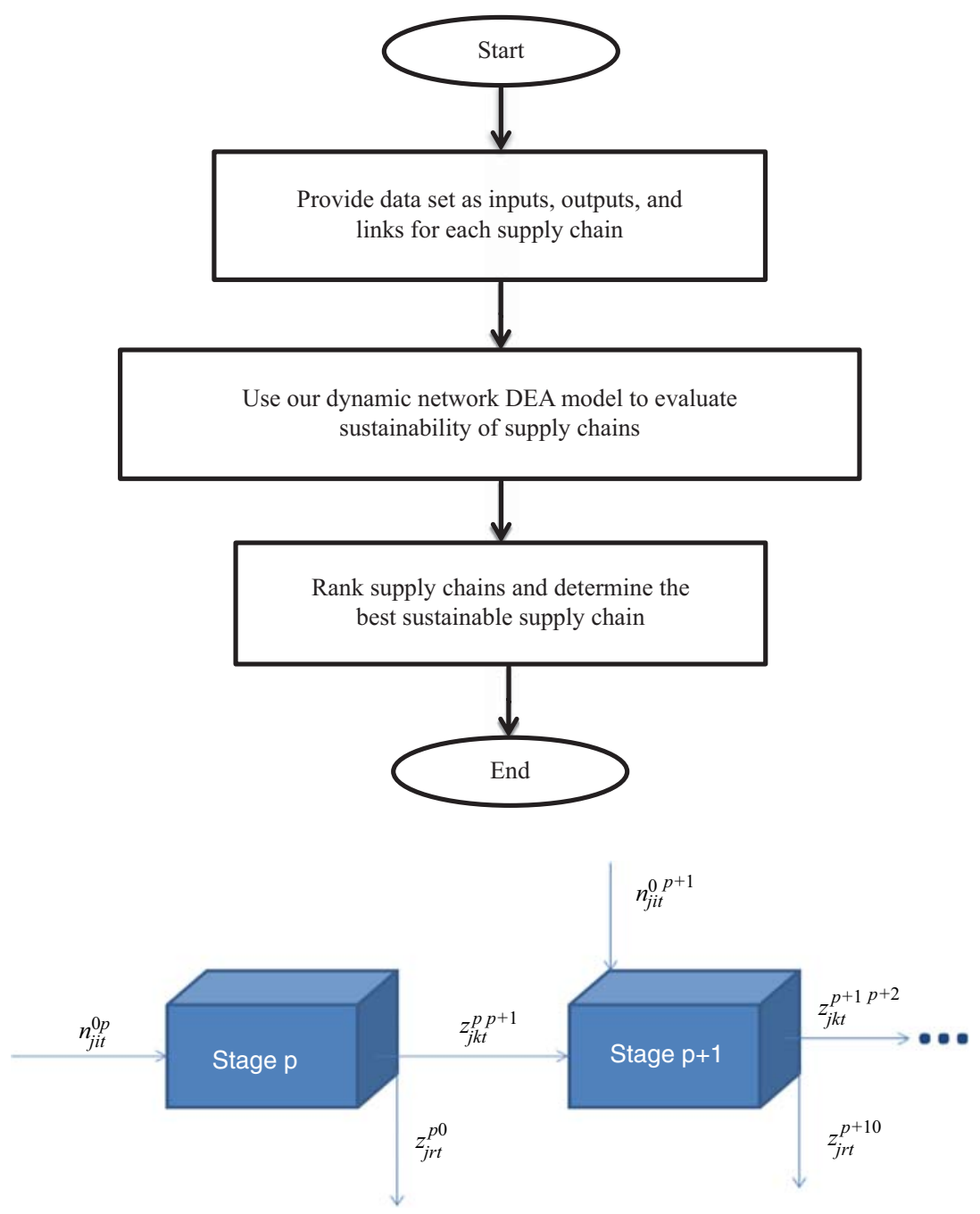

Figure 2.

Steps of the proposed framework

Figure 3. Topology of the proposed network model

Numerator of Equation (1) expresses two terms, weighted sum of outputs that exit the network as final output and also weighted sum of output which exits from the first stage and enters the second stage as input. Besides, denominator indicates weighted sum of inputs that enter stage 1 from outside. Efficiencies of other stages are defined by the following equation. Other stages can possess two types of inputs; that is inputs which enter the stage from outside and also the inputs that are outputs of prior stage and enter the stage $p$ as input:

$$
\rho_{p j}=\frac{\sum_{r=1}^{s} \lambda_{p r} z_{j r t}^{10}+\sum_{k=1}^{K} \beta_{p k} z_{j k t}^{12}}{\sum_{k=1}^{K} \beta_{p k} z_{j k t}^{12}+\sum_{i=1}^{I} \alpha_{p i} n_{j i t}^{01}}
$$

Numerator of Equation (2) expresses the weighted sum of outputs which exit the network as final output and also weighted sum of outputs that exit the stage $p$ and enter the stage $p+1$. 
IMDS

117,9

1872
Denominator indicates weighted sum of inputs that enter stage $p+1$ directly from stage $p$ and weighted sum of inputs which enter the stage $p$ from outside of network.

Now, overall efficiency of $j$ th DMU is defined in the following equation:

$$
P_{j}=\frac{\sum_{p=1}^{P}\left(\sum_{r=1}^{s} \lambda_{p r} z_{j r t}^{10}+\sum_{k=1}^{K} \beta_{p k} z_{j k t}^{12}\right)}{\sum_{p=1}^{P}\left(\sum_{k=1}^{K} \beta_{p k} z_{j k t}^{12}+\sum_{i=1}^{I} \alpha_{p i} n_{j i t}^{01}\right)}
$$

Equation (3) indicates the overall efficiency of network. Numerator of Equation (3) expresses weighted sum of all outputs including the outputs which exit the network as final outputs; and the outputs which exit stage $p$ but enter stage $p+1$ as input. Denominator indicates all inputs including inputs which go into stage $p+1$ after they leave stage $p$; and the inputs which enter the stage $p$ from outside of network.

\subsection{Proposed dynamic DEA model's structure}

At this juncture, we represent our proposed dynamic DEA model which evaluates the supply chains in which the networks have series structure. As depicted in Figure 1, we classify the links into three categories. Thus, we define desirable (good) link, undesirable (bad) link, and free link (dual-role link) as typical carry-overs among periods. Let us now define following links:

(1) Desirable (good) link: this link indicates desirable carry-over which connects th period to $t+1$ period. In our model, we maximize this kind of link.

(2) Undesirable (bad) link: this link corresponds to undesirable carry-over which connects $t$ th period to $t+1$ period. In our model, we minimize this kind of link.

(3) Free (discretionary) link: free link signifies discretionary carry-over which connects $t$ th period to $t+1$ period. This type of link has dual-role nature. This means that free link can be stated desirable or undesirable. One of the results of the model presented in this paper is that it defines nature of this type of link.

Now, factors and their weights are defined as follows:

- $\quad \mathrm{c}_{\mathrm{jlt}}^{\text {free }}(l=1, \ldots, L$ free $)$ displays free link of $j$ th DMU in $t$ th period $(t=1, \ldots, T)$ which enters into period $t+1$.

- $\quad c_{j l t}^{d}(1=1, \ldots, L d)$ indicates desirable (good) link of $j$ th DMU in $t$ th period $(t=1, \ldots, T)$ which connects to period $t+1$.

- $\quad c_{j l t}^{\text {und }}(1=1, \ldots, L$ und) shows undesirable (bad) link of $j$ th DMU in th period $(t=1, \ldots, T)$ which enters into period $t+1$.

- $\vartheta_{t l}$ is multiplier of desirable carry-over related to the free $\operatorname{link} c_{j l t}^{\mathrm{free}}$ indicating degree of desirability in free link.

- $\omega_{t t}$ is multiplier of undesirable carry-over related to the free link $c_{j l t}^{\text {free }}$ indicating degree of undesirability in free link.

- $\gamma_{t l}$ is multiplier of desirable link $c_{j l t}^{d}$.

- $\nu_{t l}$ is multiplier of undesirable link $c_{j l t}^{\mathrm{und}}$. 
Given the above discussions, overall efficiency of $j$ th network under evaluation in $t$ th period is defined as following objective function:

$$
\phi_{j}^{t}=\frac{\sum_{l=1}^{L} \gamma_{t l} c_{j l t}^{d}+\sum_{l=1}^{L} \vartheta_{t l} c_{j l t}^{\mathrm{free}}+\sum_{p=1}^{P}\left(\sum_{r=1}^{s} \lambda_{p r} z_{j r t}^{10}+\sum_{k=1}^{K} \beta_{p k} z_{j k t}^{12}\right)}{\sum_{l=1}^{L} v_{t l} c_{j l t}^{\mathrm{und}}+\sum_{l=1}^{L} \omega_{t l} c_{j l t}^{\mathrm{free}}+\sum_{p=1}^{P}\left(\sum_{k=1}^{K} \beta_{p k} z_{j k t}^{12}+\sum_{i=1}^{I} \alpha_{p i} n_{j i t}^{01}\right)}
$$

Equation (4) represents $j$ th network's efficiency ratio. In this equation, weighted values of the link are taken into account which connects the period $t$ to period $t+1$ in $j$ th network. We can distinguish $\Phi_{j}^{t}$ as two merged fractions consisting of the fraction in the second part indicating $P_{j}$ (Equation (3)) in which both numerator and denominator have parentheses and fraction without parentheses in the first part of Equation (4) which demonstrates weighted ratio of desirable links to undesirable ones. We wish to determine free links' nature in terms of being desirable or undesirable. Accordingly, we introduce the links with two multipliers. Each of these multipliers indicates whether the free links are desirable or undesirable factors. Here, we set sum of these multipliers to 1 in which multipliers signify degree of desirability or undesirability of free links:

$$
v_{t l}+\omega_{t l}=1
$$

Hence, in general, ratio of links for networks in different periods is defined as follows:

$$
\phi=\frac{\sum_{l=1}^{L} \gamma_{t l} c_{j l t}^{d}+\sum_{l=1}^{L} \vartheta_{t l} c_{j l t}^{\mathrm{free}}}{\sum_{l=1}^{L} v_{t l} c_{j l t}^{\mathrm{und}}+\sum_{l=1}^{L} \omega_{t l} c_{j l t}^{\mathrm{free}}}
$$

To optimize overall efficiency $\Phi$, a multi-stage process is needed as restrictions $\rho_{p j}, \rho_{1}$, and $\phi$ should not be more than 1 . At this juncture, given definitions and formulas, overall non-linear model is presented as follows:

$$
\operatorname{Max} \frac{\sum_{l=1}^{L} \gamma_{t l} c_{j l t}^{d}+\sum_{l=1}^{L} \vartheta_{t l} c_{j l t}^{\text {free }}+\sum_{p=1}^{P}\left(\sum_{r=1}^{s} \lambda_{p r} z_{j r t}^{10}+\sum_{k=1}^{K} \beta_{p k} z_{j k t}^{12}\right)}{\sum_{l=1}^{L} v_{t l} c_{j l t}^{\text {und }}+\sum_{l=1}^{L} \omega_{t l} c_{j l t}^{\text {free }}+\sum_{p=1}^{P}\left(\sum_{k=1}^{K} \beta_{p k} z_{j k t}^{12}+\sum_{i=1}^{I} \alpha_{p i} n_{j i t}^{01}\right)}
$$

s.t.:

$$
\begin{gathered}
\frac{\sum_{r=1}^{s} \lambda_{p r} z_{j r t}^{10}+\sum_{k=1}^{K} \beta_{p k} z_{j k t}^{12}}{\sum_{k=1}^{K} \beta_{p k} z_{j k t}^{12}+\sum_{i=1}^{I} \alpha_{p l} n_{j i t}^{01}} \geqslant 1 \\
\frac{\sum_{l=1}^{L} \gamma_{t l} c_{j l t}^{d}+\sum_{l=1}^{L} \vartheta_{t l} c_{j l t}^{\mathrm{free}}}{\sum_{l=1}^{L} v_{t l} c_{j l t}^{\mathrm{und}}+\sum_{l=1}^{L} \omega_{t l} c_{j l t}^{\mathrm{free}}} \geqslant 1 \\
\vartheta_{t l}+\varpi_{t l}=1 \\
\gamma_{t l} \geqslant 0, \vartheta_{t l} \geqslant 0, \lambda_{p r} \geqslant 0, \beta_{p k} \geqslant 0, v_{t l} \geqslant 0, \omega_{t l} \geqslant 0, \alpha_{p i} \geqslant 0 .
\end{gathered}
$$

Formulas (2), (4), (5), and (6) are incorporated into model (7). Non-linear model (7) includes formula (4) in the objective function. Formula (2) is used as the first constraint and formula (5) and (6) are applied in second constraint. Model (7) is a non-linear model which should be converted to a linear model. Charnes-Cooper approach may be utilized to convert the 
IMDS 117,9

non-linear models to linear models (Charnes et al., 1978). The $o$ in our proposed model (8) implies the DMU under evaluation:

$$
\operatorname{Max} \sum_{l=1}^{L} \gamma_{t l} c_{o l t}^{d}+\sum_{l=1}^{L} \vartheta_{t l} c_{o l t}^{\mathrm{free}}+\sum_{p=1}^{P}\left(\sum_{r=1}^{s} \lambda_{p r} z_{o r t}^{10}+\sum_{k=1}^{K} \beta_{p k} z_{o k t}^{12}\right)
$$

s.t.:

$$
\begin{gathered}
\sum_{l=1}^{L} v_{t l} c_{o l t}^{\mathrm{und}}+\sum_{l=1}^{L} \varpi_{t l} c_{\text {olt }}^{\mathrm{free}}+\sum_{p=1}^{P}\left(\sum_{k=1}^{K} \beta_{p k} z_{o k t}^{12}+\sum_{i=1}^{I} \alpha_{p i} n_{o i t}^{01}\right)=1 \\
\sum_{l=1}^{L} v_{t l} c_{\text {olt }}^{\mathrm{und}}+\sum_{l=1}^{L} \varpi_{t l} c_{\text {olt }}^{\mathrm{free}}+\sum_{p=1}^{P}\left(\sum_{k=1}^{K} \beta_{p k} z_{o k t}^{12}+\sum_{i=1}^{I} \alpha_{p i} n_{\text {oit }}^{01}\right)=1 \\
\sum_{r=1}^{s} \lambda_{p r} z_{j r t}^{10}+\sum_{k=1}^{K} \beta_{p k} z_{j k t}^{12} \leqslant \sum_{k=1}^{K} \beta_{p k} z_{j k t}^{12}+\sum_{i=1}^{I} \alpha_{p i} n_{j i t}^{01} \\
\sum_{l=1}^{L} \gamma_{t l} c_{j l t}^{d}+\sum_{l=1}^{L} \vartheta_{t l}^{\mathrm{free}} \leqslant \sum_{j l t}^{L} v_{t l}^{\mathrm{und}}+\sum_{l=1}^{L} \omega_{t l} c_{j l t}^{\mathrm{free}} \\
\vartheta_{t l}+\varpi_{t l}=1 \\
\gamma_{t l} \geqslant 0, \vartheta_{t l} \geqslant 0, \lambda_{p r} \geqslant 0, \beta_{p k} \geqslant 0, v_{t l} \geqslant 0, \omega_{t l} \geqslant 0, \alpha_{p i} \geqslant 0 .
\end{gathered}
$$

The objective function in model (8) indicates DMU's efficiency score in the period under evaluation. Furthermore, to illustrate weighted average of network efficiency during several periods, so the following expression is presented:

$$
\begin{gathered}
\Phi_{j}=\sum_{t=1}^{T} \mathrm{w}^{t} \phi_{j}^{t} \Phi_{j}=\sum_{t=1}^{T} \mathrm{w}^{t} \phi_{j}^{t} \\
\sum_{t=1}^{T} w^{t}=1
\end{gathered}
$$

In next section, a case study is given.

\section{Case study}

Delpazir Company is a private holding company in food industry which was established in 1980 in Iran. The company's main products include tomato paste and tomato sauce. Delpazir Company has 17 branches in different provinces of Iran. Each branch has a separate supply chain which produces tomato paste. The supply chains are assessed and controlled under supervision of Delpazir Company holding. Delpazir group has the most advanced and up-to-date food processing factories across the Middle East enjoying the 
most advanced European machinery with top technology in food industry. Delpazir group is comprised of three major sectors as follows:

(1) Kadbanoo Co. with more than 61 years of experience in food industry does the production and outsourcing of Delpazir products encompassing more than 50 stock keeping units including mayonnaise and salad dressings, canned food, tea, tomato paste, and ketchup.

(2) Imports and exports are executed by Akam Co. Akam exports various products to neighbor countries.

(3) Sales and distribution is performed by Pegah Co. With 29 years of experience, Pegah Co. is operating with more than 150 SKU's and 4 major brands in fast moving consumer goods industry. Pakhsh Pegah was established in 1983 and is responsible for distribution, sales and marketing of domestic and foreign products across Iran. This company distributes products through 14 distribution centers across Iran and has always been a pioneer in distribution industry.

In this paper, sustainability of 17 supply chains is assessed during 2012 to 2014 . To assess sustainability of supply chains, economic, environmental, and social factors are taken into account. Each supply chain has three stages including farms, canning factories, and chain stores. Inputs and outputs of supply chains given three stages are defined below:

(1) Inputs and outputs of farms:

- Inputs:

- Environmental costs $(\$ 1,000)$ as an environmental criterion which represents amount of money that is paid for environmental damage in a year.

- Cost of labor safety $(\$ 1,000)$ as a social criterion which represents amount of money that is for compensating labor damages in a year.

- Other costs (economic criterion).

- Outputs:

- Revenue from sales of tomatoes as raw material which are sent to tomato-paste factory $(\$ 1,000)$ as an economic criterion.

- Revenue from sales of raw tomatoes in markets $(\$ 1,000)$ as the other economic criterion.

(2) Inputs and outputs of canning factories:

- Inputs:

- Cost of purchasing tomato from farm $(\$ 1,000)$ as an economic criterion.

- Environmental costs $(\$ 1,000)$ as an environmental criterion which is amount of money that is paid for environmental damage in a year.

- Cost of labor safety $(\$ 1,000)$ as a social criterion which is amount of money that is paid for compensating labor damage in a year.

- Outputs:

- Volume of tomato pastes which are ready for sales (economic criterion) in a year.

(3) Inputs and outputs of chain stores:

- Inputs:

- Volume of tomato pastes which are ready for sales (economic criterion) in a year.

- Shipping costs $(\$ 1,000)$ as an economic criterion.
A dynamic approach 
IMDS

117,9

1876
- Cost of labor safety $(\$ 1,000)$ as a social criterion which represents amount of money that is paid for compensating labor damage during a year.

- Outputs:

- Annual profit $(\$ 1,000)$ as an economic criterion.

Degree of customer satisfaction (as a social criterion) which is measured by nine-point Likert scale. Table I shows Likert scale (Likert, 1932). Delpazir Co. utilizes opinions of customers to measure customer satisfaction.

Given the aforementioned definitions of inputs, outputs, and links, structure of supply chains is displayed in Figure 4.

Furthermore, as is shown in Figure 5, each period has three links to next period which are as follows:

(1) Not collected revenue (desirable link).

(2) Unpaid costs (undesirable link).

(3) Green research and development (green R\&D) (free/dual-role link). In Delpazir Company, green R\&D costs are paid for elimination of chemical and non-organic processes from tomato supply chain.

Historical data of 17 supply chains from 2012 to 2014 are reported in Table II. The data set is obtained through recorded documents of Delpazir Company as well as the company's executives. Note that there are 17 supply chains of Delpazir Company in 17 provinces of Iran. They operate separately and independently while being directed by a central ownership.

\begin{tabular}{ll}
\hline Value & Customer satisfaction \\
\hline 9 & High satisfaction \\
7 & Good satisfaction \\
5 & Medium satisfaction \\
3 & Low satisfaction \\
1 & Very low satisfaction \\
$2-4-6-8$ & Intermediate factors
\end{tabular}

Figure 4.

Structure of supply chains

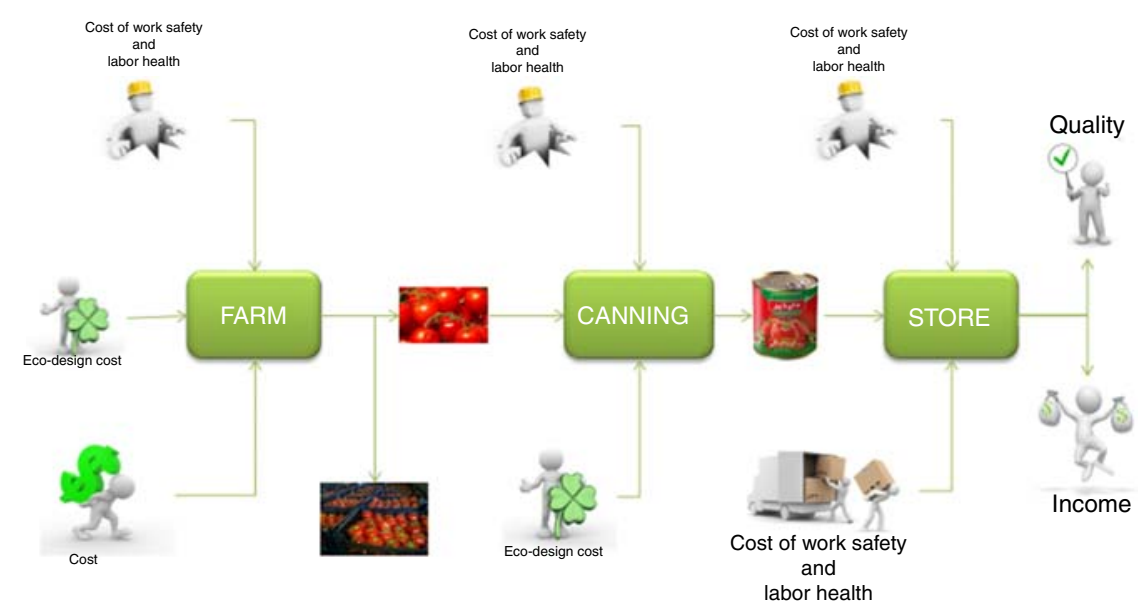



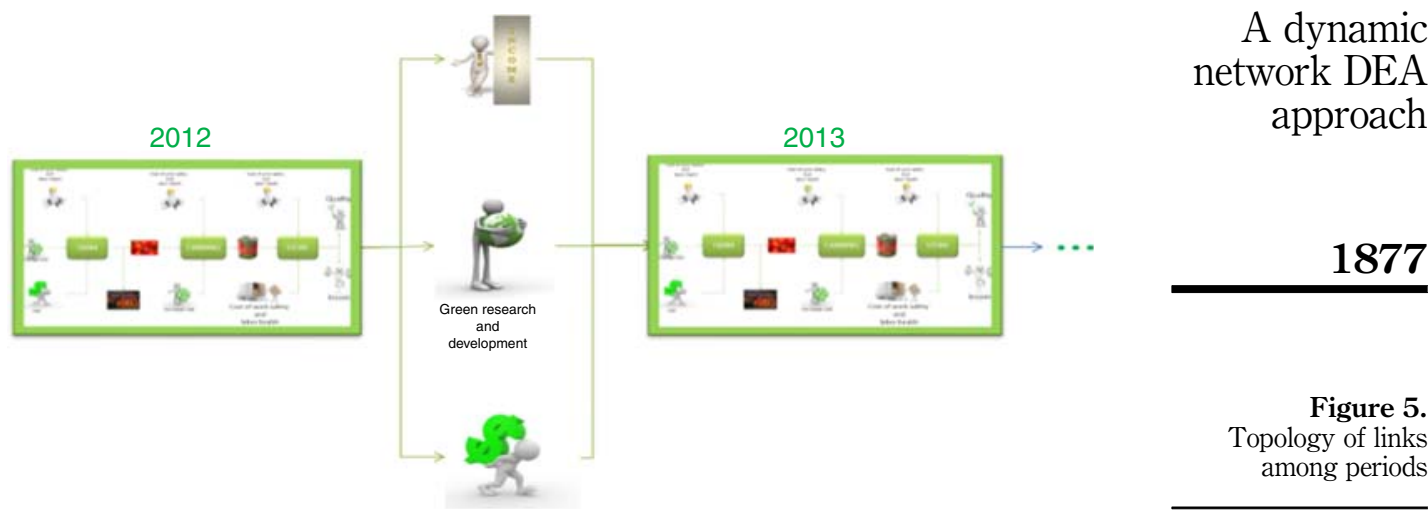

1877

Figure 5.

Topology of links among periods

By running model (7), the supply chains are assessed over three years. Efficiency scores of 17 supply chains in three years are shown in Table III. Besides, nature of the dual-role links is identified in all supply chains.

According to Table III, if the $\vartheta$ becomes 1, the dual-role link has desirable nature. If the $\varpi$ becomes 1 , the link has undesirable nature. However, some sustainable supply chains may seem superior due to excellent efficiency scores only in a specific period. For example, in 2013, supply chains 15 and 16 are more sustainable than other supply chains. But, given overall efficiency, they are ranked as 7th and 8th, respectively. Though supply chains 17, 13, 9, and 4 are not sustainable in any period, they have received a better rank compared with supply chains 15 and 16 . Given overall efficiency, the supply chain 5 is the most sustainable supply chain during all periods.

\section{Conclusions}

\subsection{Obtained results}

The traditional DEA models do not explicitly ascertain any of key sub-processes involved in divisions of supply chains. Furthermore, one of the drawbacks of these models is oversight of internal structure of supply chains (DMUs). As an illustration, numerous companies embrace several divisions that are linked to each other having division-specific inputs and outputs along with links to other divisions. It is recognized that supply chains (DMUs) may have multi-stage structures where initial stage utilizes inputs to produce outputs that become inputs of the second stage and the second stage employs the first stage outputs to produce its own outputs. On the other hand, there exist several sustainability criteria complicating SCM's evaluation. Accordingly, these make decision-makers encounter some discretionary/free and even contradictory criteria while evaluating sustainability of SCM. Dual-role links, inputs, desirable and undesirable outputs are some of main criteria.

To deal with multiple criteria, we proposed a novel method to consider interactions among supply chains and overall efficiencies in network-dynamic DEA. This enables decision makers not only to acquire the overall efficiency of supply chains (DMUs) over entire periods, but also to observe dynamic change of period efficiency and dynamic change of divisional efficiency of DMUs. Our approach excellently overcomes deficiencies of previous methods. We have also extended and improved Tone and Tsutsui (2014) dynamic DEA model. In our proposed approach, overall values of carry-overs for each network are obtained and afterwards are entered to succeeding period. In other words, Tone and Tsutsui (2014) connected the stages to each other (among periods) but we connect each network (as a whole) to other networks. Here, in addition, free links among periods are defined in terms of desirable and undesirable carry-overs. Numerical illustrations have been provided in a case study to demonstrate 
\begin{tabular}{l} 
IMDS \\
117,9 \\
$\mathbf{1 8 7 8}$ \\
\hline
\end{tabular}

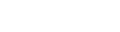




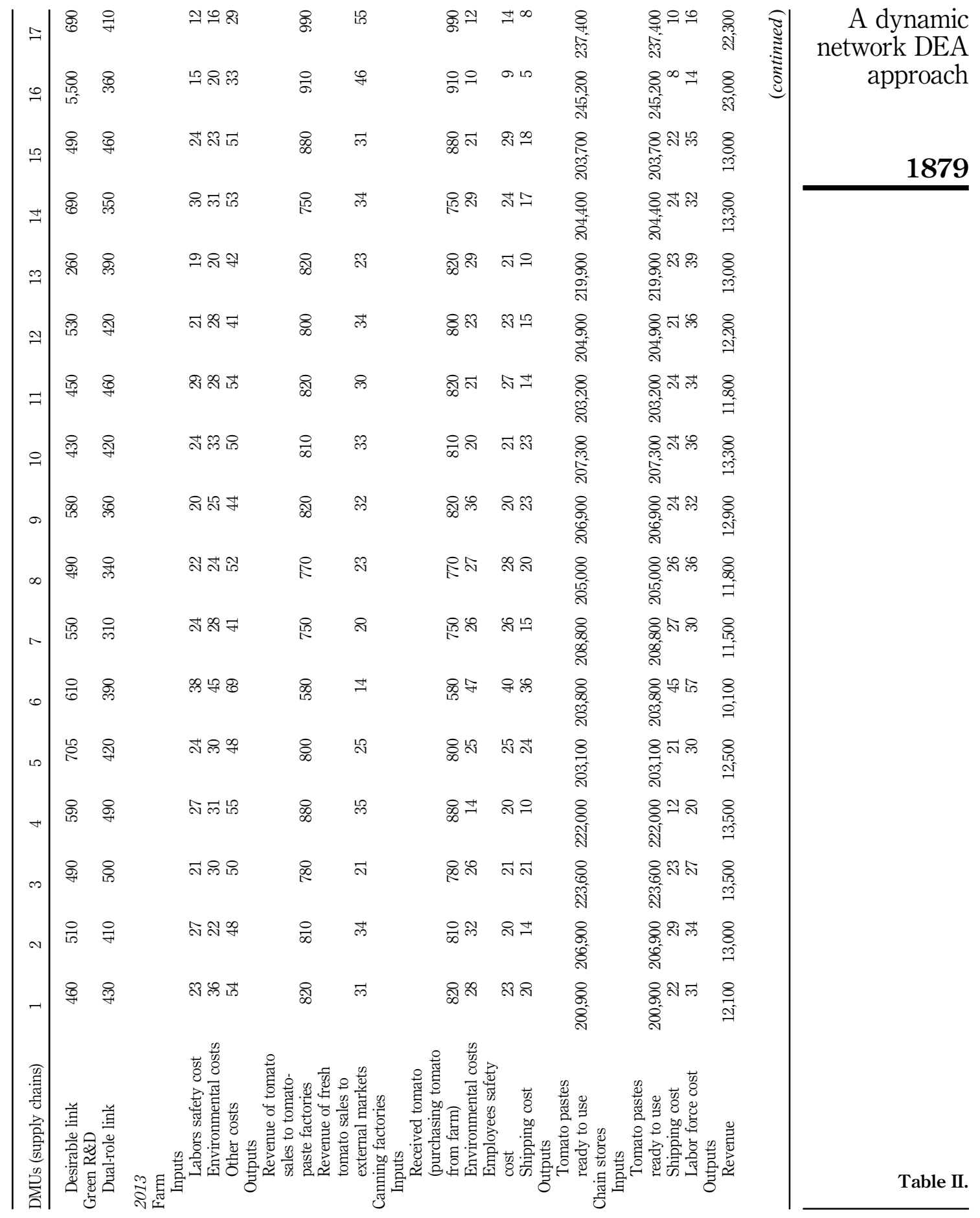




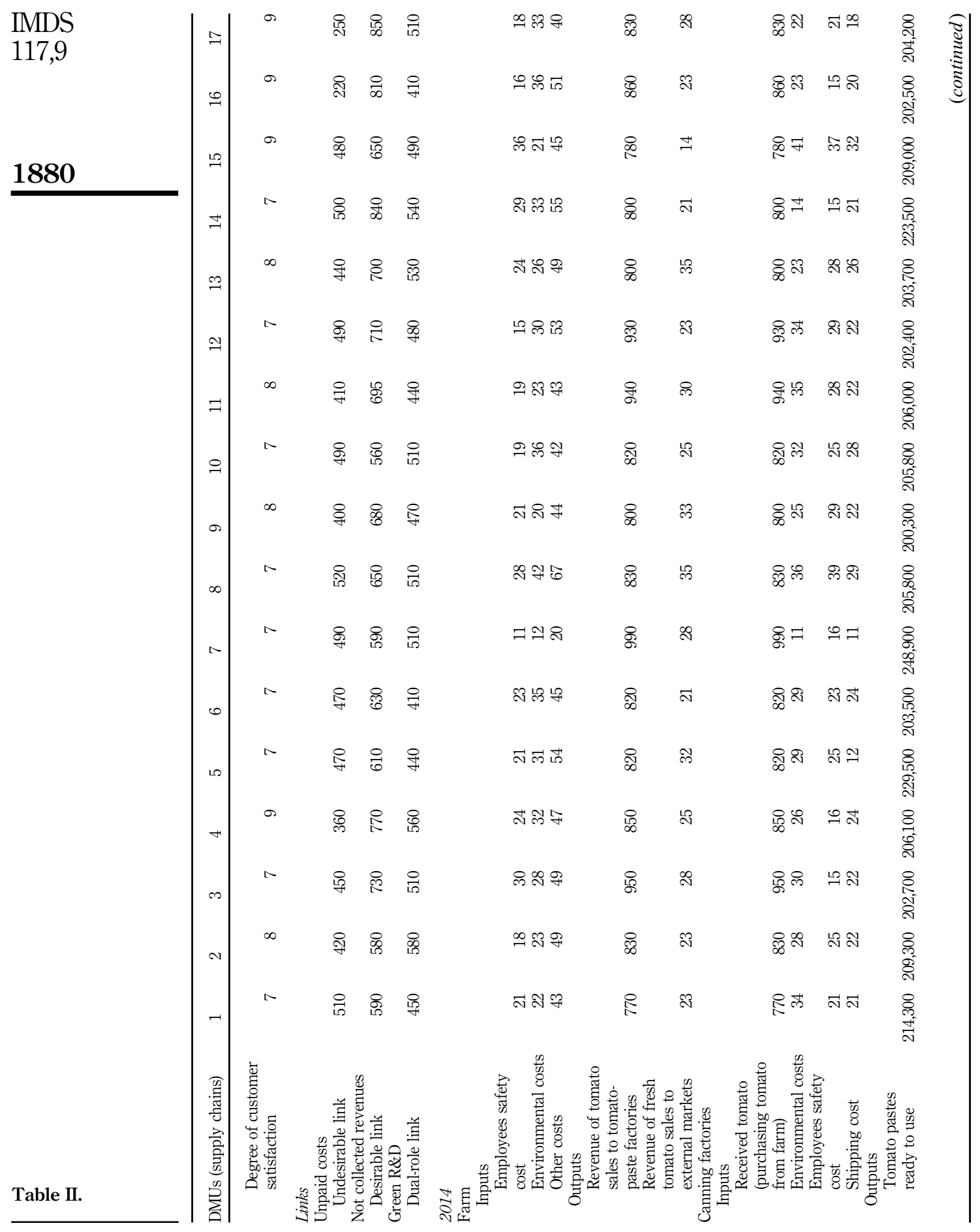




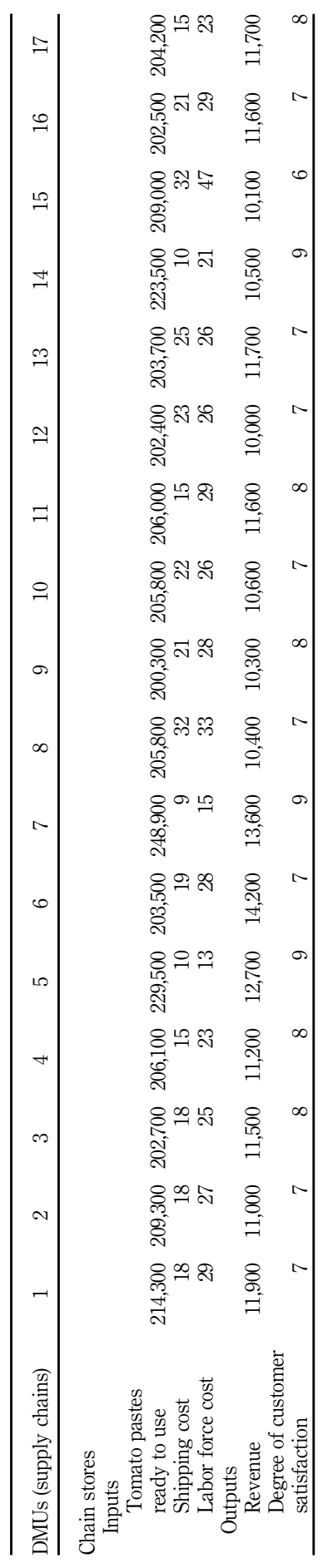

A dynamic network DEA approach

1881

Table II. 
IMDS

117,9

1882

\begin{tabular}{|c|c|c|c|}
\hline$\approx$ & $\stackrel{\infty}{\infty}-10$ & $\stackrel{\sigma}{\sigma}-0$ & Oे \\
\hline$\bullet$ & $\stackrel{8}{\circ} \circ-$ & $-1 \rightarrow 0$ & $\begin{array}{l}\mathbb{N} \infty \\
0 \circ \infty\end{array}$ \\
\hline 10 & $\stackrel{\mathscr{O}}{0}+0$ & $\neg \rightarrow 0$ & שீ \\
\hline$\exists$ & $\stackrel{+}{\infty}$ & $\vec{\sigma}+0$ & \\
\hline 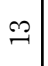 & $\stackrel{\infty}{\infty} \rightarrow 0$ & 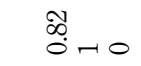 & \\
\hline$\stackrel{\sim}{\exists}$ & 뇽ㅇ & $\stackrel{\infty}{0}-0$ & \\
\hline$\exists$ & 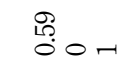 & $\stackrel{\theta}{0} \rightarrow 0$ & \\
\hline 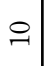 & $\stackrel{8}{\circ} \circ-$ & 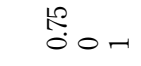 & مص \\
\hline os & $\mathscr{O}_{0}^{\infty}$ & 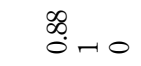 & \\
\hline$\infty$ & $\stackrel{0}{\infty}$ & $छ 0-$ & \\
\hline$\sim$ & 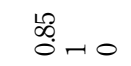 & $\stackrel{\vec{\sigma}}{\dot{O}} \rightarrow 0$ & \\
\hline 0 & $\stackrel{\mathscr{O}}{0}+0$ & 范。ー & \\
\hline$\llcorner 0$ & $\neg-0$ & $\vec{\sigma}+0$ & \\
\hline$H$ & $\stackrel{\mathscr{S}}{\circ} \rightarrow 0$ & $\stackrel{\mathscr{B}}{\circ}-0$ & \\
\hline$\infty$ & I্: & $\stackrel{\infty}{\infty}-10$ & \\
\hline$\sim$ & : & 太્ત૦ & \\
\hline-1 & E̊ : & $\stackrel{\Delta}{0}$ & 莒足。 \\
\hline 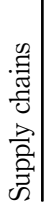 & 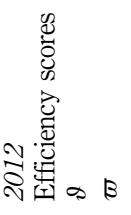 & 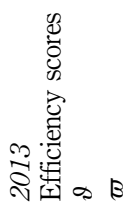 & 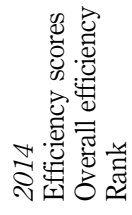 \\
\hline
\end{tabular}

Table III.

Efficiency scores of 17 supply chains in three years 
applicability of the proposed approach. We examined performance of seventeen supply chains of Delpazir Company in 17 provinces of Iran in 2012-2014.

Case study was run to evaluate performance of supply chains in several periods. Results of analysis (feedback) are put into practice by decision makers. The most sustainable supply chains are benchmarked by other supply chains. Based on the efficiency scores of Table III, the supply chain No. 5 is ranked 1st, 6th, and 4th in 2012, 2013, and 2014, respectively. Furthermore, the supply chain No. 5 is ranked as the most sustainable supply chain with overall efficiency score of 0.95 . Similarly, the supply chains Nos 7 and 17 are ranked as 2nd and 3rd, respectively. The reason why the supply chain No. 5 is superior in ranking is based on the fact that its efficiency score in all years is at a high and acceptable level. Therefore, the overall efficiency of this supply chain is the highest in comparison with the other supply chains. It is noteworthy to state that if we wish to rank the supply chains only based on the efficiency scores in 2014, the supply chain No. 5 would be ranked 4th and in 2013 would be ranked as 6th. The supply chains Nos 15 and 16 are introduced as superior supply chains in 2013, but since this superiority is not sustainable in the years before and after, these supply chains cannot get an overall rank better than 7th and 8th, respectively (Figure 6).

\subsection{Managerial implications}

Note that the main noticeable outcome of this study is to present a more reliable and realistic model as a novel integrated network dynamic DEA framework for dealing with some shortcomings of the previous models in assessing SSCM. Our proposed method offers a means for managers to monitor and measure efficiency of their production processes.

In recent years, SCM has increasingly become of great importance. Process of evaluation and selection of SCM is one of the most dominant tasks of managers in field of sustainable supply chain. Since decision makers should take into account economic, social, and environmental criteria, these criteria should be identified by decision makers. A variety of mathematical modeling approaches have been utilized in assessing sustainability of supply chains. Mathematical models convert data into information to facilitate strategic and operational decisions. All former approaches, except for DEA, rely on subjective weights of criteria determined by managers. The approach presented in this paper evaluates sustainability of supply chains over multiple periods.

In addition to assessing sustainability of supply chains, in this paper, our model can propose improvement solutions for each inefficient network in any period. Moreover, using the proposed model, weaknesses in each network and in its stages are specified. In Table IV,
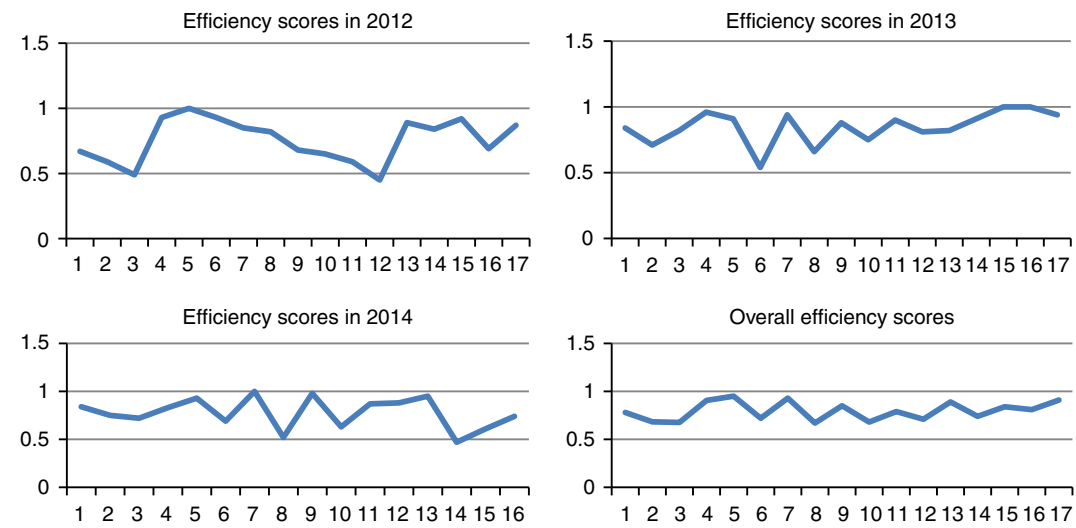

A dynamic network DEA approach

1883
Figure 6. Supply chains' efficiency score 


\begin{tabular}{l} 
IMDS \\
117,9 \\
$\mathbf{1 8 8 4}$ \\
\hline
\end{tabular}

Table IV.

Improvement solutions for inefficient supply chains

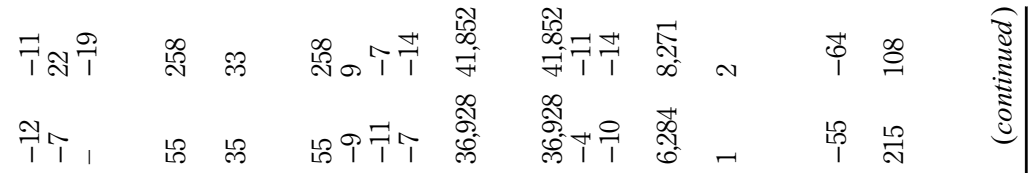

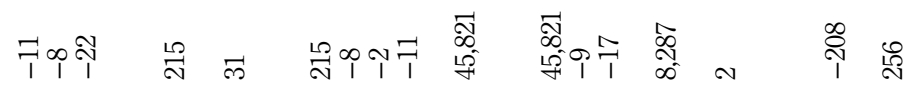

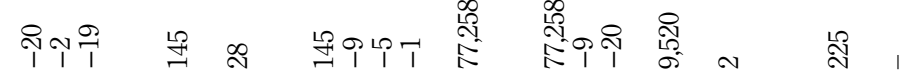

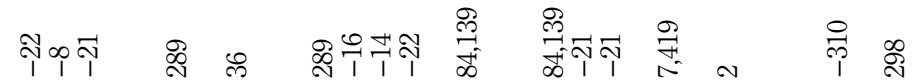

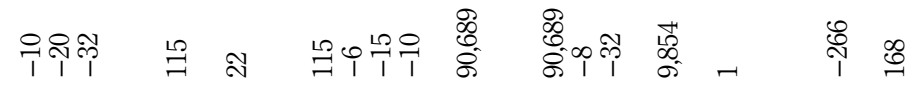

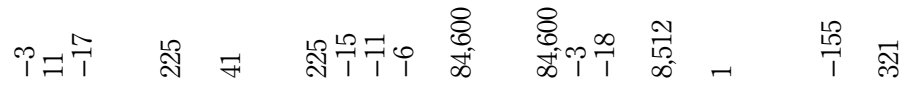
个品 쿵 \& एNำ

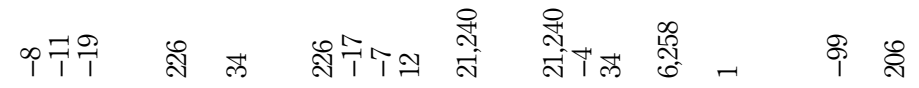
rip 㞼

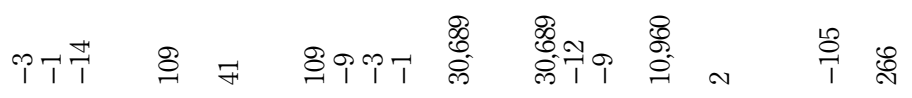
№ฺ कơ

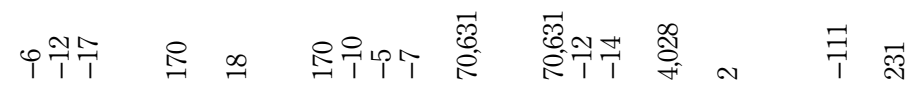

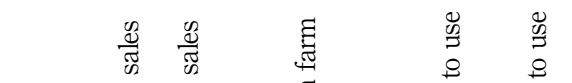

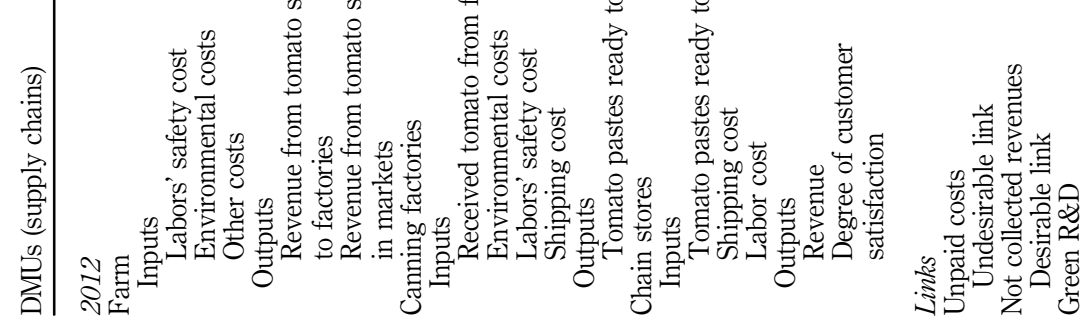




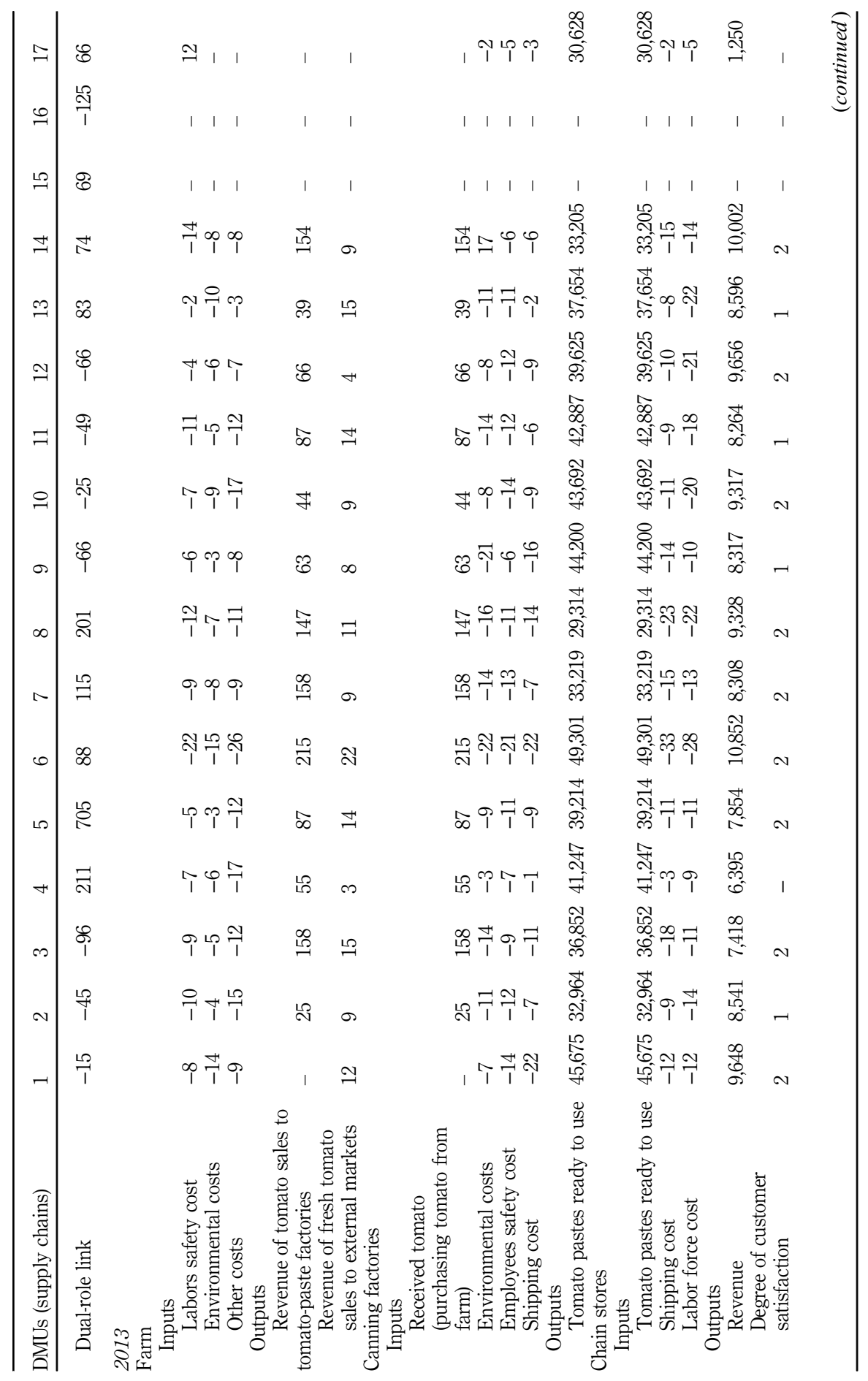

A dynamic network DEA approach

1885

Table IV. 
\begin{tabular}{l} 
IMDS \\
117,9 \\
$\mathbf{1 8 8 6}$ \\
\hline
\end{tabular}

근

$\therefore$

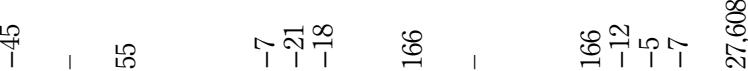

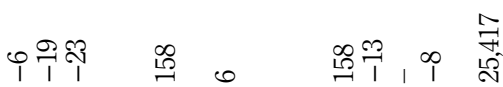

จีคก ฒ

象

I 1

売 黑

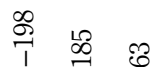

ำำ กิ

$\stackrel{1}{\sim}$

ำ

1

获

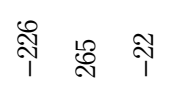

整学

苧芯品

귝

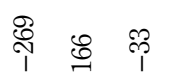

누눙

ㄱำ

구우오

논 농

$\forall \rightarrow \infty$

ิํㅇ \&

$\stackrel{\infty}{1}$

突 声

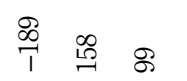

우오ํ

$\sim$

Table IV. 
improvement solutions for inefficient supply chains are provided. As is seen, it is reported that what changes are needed for each DMU in each period to make them efficient. Negative values represent reduction in inputs. Positive values imply an increase in outputs. In addition, the factors that do not need to be changed are indicated by "-."

As is seen in Table IV, for the efficient supply chains no improvement is required. By measuring division efficiency, managers can compare divisions with their competitors. Furthermore, our suggested approach helps managers to determine status of dual-role factors.

\subsection{Theoretical contributions and future research directions}

NDEA has been developed to model the networks' complexity, whereas traditional DEA models cannot measure supply chains' efficiency with network structures. By estimating the efficiency of the networks, one can get further insights from obtained results and can take proper actions and develop applicable policy to improve sustainability. This paper proposed a network-dynamic DEA model. Using the suggested model, sustainable supply chains were assessed in multiple periods. We determined free links' nature in multiple periods. Moreover, the links' values in multiple periods were used in calculating efficiency of supply chains. One of the main advantages of dynamic DEA is to evaluate DMUs in multiple periods. In this paper, we reached following findings:

- a new additive model of network-dynamic DEA was developed;

- based on series approach, temporal links among network were established;

- nature of free links was determined; and

- the links were outlined in a way that carry-overs of networks are connected in different periods and not in different stages.

Limitations and strengths of this paper can be defined as follows: it is always a big challenge to apprehend complexities of real world in a theoretical model. Accordingly, $\mathrm{n}$ real world problems where there are millions of DMUs to be evaluated, we need an approach to deal with big data. In this paper, we did not develop an approach for dealing with big data. The main strengths of this study are two-folds. First, we developed a network and dynamic DEA model for defining free links among periods in terms of desirable and undesirable carry-overs and also connected each network to other networks. Second, we established a novel way for considering multi-stage processes which complements and increases value of two-stage DEA method.

Our approach can be extended for networks with parallel and series-parallel structure. Extending our model using fuzzy data is another research topic. Finally, we recommend prospective researchers to work on DEA models to deal with big data.

\section{References}

Ageron, B., Gunasekaran, A. and Spalanzani, A. (2012), "Sustainable supply management: an empirical study", International Journal of Production Economics, Vol. 140 No. 1, pp. 168-182.

Azadi, M., Jafarian, M., Farzipoor Saen, R. and Mirhedayatian, S.M. (2015), “A new fuzzy DEA model for evaluation of efficiency and effectiveness of suppliers in sustainable supply chain management context", Computers \& Operations Research, Vol. 54, pp. 274-285.

Bai, C. and Sarkis, J. (2010), "Integrating sustainability into supplier selection with grey system and rough set methodologies", International Journal of Production Economics, Vol. 124 No. 1, pp. 252-264.

Charnes, A., Cooper, W.W. and Rhodes, E. (1978), "Measuring the efficiency of decision making units", European Journal of Operational Research, Vol. 2 No. 6, pp. 429-444.

\section{A dynamic network DEA approach}


IMDS 117,9

Chen, C. and Yan, H. (2011), "Network DEA model for supply chain performance evaluation", European Journal of Operational Research, Vol. 213 No. 1, pp. 147-155.

Chen, Y., Liang, L. and Yang, F. (2006), "A DEA game model approach to supply chain efficiency", Annals of Operations Research, Vol. 145 No. 1, pp. 35-49.

Cook, W.D., Zhu, J. and Yang, F. (2010), "Network DEA: additive efficiency decomposition", European Journal of Operational Research, Vol. 207 No. 2, pp. 1122-1129.

Dyllick, T. and Hockerts, K. (2002), "Beyond the business case for corporate sustainability", Business Strategy and the Environment, Vol. 11 No. 2, pp. 130-141.

Färe, R. and Grosskopf, S. (1996), "Productivity and intermediate products: a frontier approach", Economics Letters, Vol. 50 No. 1, pp. 65-70.

Färe, R. and Grosskopf, S. (2000), "Network DEA”, Socio-Economic Planning Sciences, Vol. 4 No. 1, pp. 35-49.

Färe, R., Grosskopf, S. and Whittaker, G. (2007), "Network DEA", in Zhu, J. and Cook, W.D. (Eds), Modeling Data Structures Irregularities and Structural Complexities in Data Envelopment Analysis, Chapter 12, Springer, New York, NY, pp. 209-240.

Govindan, K., Jafarian, A. and Nourbakhsh, V. (2015), "Bi-objective integrating sustainable order allocation and sustainable supply chain network strategic design with stochastic demand using a novel robust hybrid multi-objective metaheuristics", Computers \& Operations Research, Vol. 62, pp. 112-130.

Govindan, K., Khodaverdi, R. and Jafarian, A. (2013), “A fuzzy multi criteria approach for measuring sustainability performance of a supplier based on triple bottom line approach", Journal of Cleaner Production, Vol. 47, pp. 345-354.

Kao, C. and Hwang, S.N. (2010), "Efficiency measurement for network systems: IT impact on firm performance", Decision Support Systems, Vol. 48 No. 3, pp. 437-446.

Khodakarami, M., Shabani, A., Farzipoor Saen, R. and Azadi, M. (2015), "Developing distinctive two stage data envelopment analysis models: an application in evaluating the sustainability of supply chain management", Measurement, Vol. 70, pp. 62-74.

Lewis, H.F. and Sexton, T.R. (2004), "Network DEA: efficiency analysis of organizations with complex internal structure", Computers \& Operations Research, Vol. 31 No. 9, pp. 1365-1410.

Liang, L., Yang, F., Cook, W.D. and Zhu, J. (2006), "DEA models for supply chain efficiency evaluation”, Annals of Operations Research, Vol. 145 No. 1, pp. 35-49.

Likert, R. (1932), “A technique for the measurement of attitudes”, Archives of Psychology, Vol. 22 No. 140 , pp. $1-55$.

Noorizadeh, A., Mahdiloo, M. and Farzipoor Saen, R. (2011), "Supplier selection in the presence of dual-role factors, non-discretionary inputs and weight restrictions", International Journal of Productivity and Quality Management, Vol. 8 No. 2, pp. 134-152.

Rashidi, K., Shabani, A. and Farzipoor Saen, R. (2015), "Using data envelopment analysis for estimating energy saving and undesirable output abatement: a case study in the organization for economic co-operation and development (OECD) countries", Journal of Cleaner Production, Vol. 105, pp. 241-252.

Sengupta, J.K. (1995), Dynamics of Data Envelopment Analysis, Kluwer Academic Publishers, Dordrecht.

Seuring, S. and Müller, M. (2008), "From a literature review to a conceptual framework for sustainable supply chain management", Journal of Cleaner Production, Vol. 16 No. 15, pp. 1699-1710.

Sueyoshi, T. and Goto, M. (2010), "Should the US clean air act include CO2 emission control? Examination by data envelopment analysis", Energy Policy, Vol. 38 No. 10, pp. 5902-5911.

Tavassoli, M., Faramarzi, G.R. and Farzipoor Saen, R. (2014), "Efficiency and effectiveness in airline performance using a SBM-NDEA model in the presence of shared input", Journal of Air Transport Management, Vol. 34, pp. 146-153.

Tone, K. and Tsutsui, M. (2010), "Dynamic DEA: a slacks-based measure approach”, Omega, Vol. 38 Nos 3-4, pp. 145-156. 
Tone, K. and Tsutsui, M. (2014), "Dynamic DEA with network structure: a slacks-based measure approach”, Omega, Vol. 42 No. 1, pp. 124-131.

Tseng, M.L., Lim, M. and Wong, W.P. (2015), "Sustainable supply chain management: a closed-loop network hierarchical approach”, Industrial Management \& Data Systems, Vol. 115 No. 3, pp. 436-461.

Wong, W.P., Jaruphongsa, W. and Lee, L.H. (2008), "Supply chain performance measurement system: a Monte Carlo DEA-based approach", International Journal of Industrial and Systems Engineering, Vol. 3 No. 2, pp. 162-188.

Wong, W.P. and Wong, K.Y. (2007), "Supply chain performance measurement system using DEA modeling”, Industrial Management \& Data Systems, Vol. 107 No. 3, pp. 361-381.

Wu, K.J., Liao, C.J., Tseng, M.L. and Chiu, K.K.S. (2016), "Multi-attribute approach to sustainable supply chain management under uncertainty", Industrial Management \& Data Systems, Vol. 116 No. 4, pp. $777-800$.

Yousefi, S., Shabanpour, H. and Farzipoor Saen, R. (2015), "Selecting the best supply chain by goal programming and network data envelopment analysis", RAIRO-Operations Research, Vol. 49 No. 3, pp. 601-617.

Yousefi, S., Shabanpour, H., Fisher, R. and Farzipoor Saen, R. (2016), "Evaluating and ranking sustainable suppliers by robust dynamic data envelopment analysis", Measurement, Vol. 83, pp. $72-85$.

Yu, M.M. and Lin, E.T.J. (2008), "Efficiency and effectiveness in railway performance using a multi-activity network DEA model", Omega, Vol. 36 No. 6, pp. 1005-1017.

Yu, M.M., Ting, S.C. and Chen, M.C. (2010), "Evaluating the cross-efficiency of information sharing in supply chains", Expert Systems with Applications, Vol. 37 No. 4, pp. 2891-2897.

Zhu, Q., Sarkis, J. and Geng, Y. (2005), "Green supply chain management in China: pressures, practices and performance", International Journal of Operations \& Production Management, Vol. 25 No. 5, pp. $449-468$.

\section{Corresponding author}

Reza Farzipoor Saen can be contacted at: farzipour@yahoo.com
A dynamic network DEA approach

For instructions on how to order reprints of this article, please visit our website:

www.emeraldgrouppublishing.com/licensing/reprints.htm

Or contact us for further details: permissions@emeraldinsight.com 